\title{
1 A structural biorhythm related to human sexual dimorphism
}

$6 \quad{ }^{1}$ School of Anthropology and Conservation, University of Kent, Canterbury, UK. CT2

$87 N Z$

10

11

12

13

14

15

16

17

18

19

20

21

22

23

24

25

26

27

28

29

30

31

32

33

34

35

36

37

38

39

40

41

42

43

44

45

46

47

48
${ }^{2}$ Department of Anthropology, The Ohio State University, Columbus, OH, 43210. USA.

${ }^{3}$ School of Archaeology and Anthropology, Australian National University, Canberra,

ACT 2601, Australia

\section{Correspondence}

Patrick Mahoney,

School of Anthropology and Conservation,

University of Kent,

Canterbury, UK. CT2 7NR

T: +44 12277647927

E: p.mahoney@kent.ac.uk 
Periodicity of incremental marking in human enamel

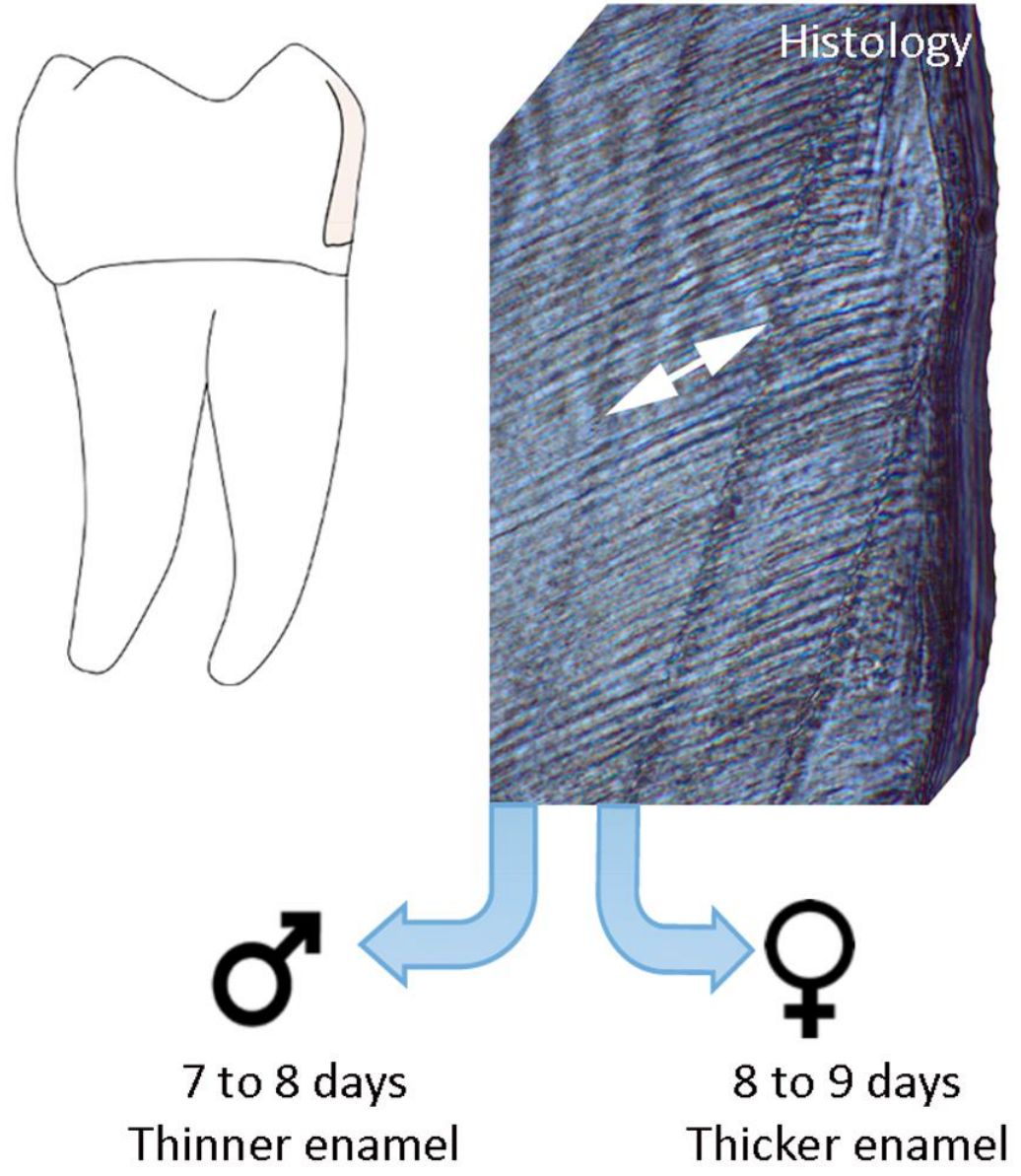

Periodicity relates to dimorphism in enamel thickness 


\section{ABSTRACT}

72 Life on earth is regulated by biological rhythms, some of which oscillate with a 73 circadian, monthly or lunar cycle. Recent research suggests that there is a near weekly

74 biorhythm that may exert an influence on human skeletal growth. Evidence for the 75 timing of this biorhythm is retained in tooth enamel as the periodicity of Retzius lines. 76 Studies report that Retzius periodicity (RP) relates to adult human stature and enamel 77 thickness. Adult human stature is sexually dimorphic, and so is enamel thickness of maxillary third molars (M3) but not mandibular M3. Yet, previous studies report sex differences in RP are apparent in some populations but not others, and it is unknown if dimorphism in enamel thickness relates to RP. To further our understanding of this biorhythm we analysed sex-related variation in RP and its relationship with enamel thickness in a sample of M3's ( $n=94)$ from adults in Northern Britain. Results reveal RP was significantly higher in our sample of female molars compared to those of males, which is consistent with the previously reported correlation between the biorhythm and adult stature. The RP of maxillary M3 related to sex differences in enamel thickness, but this relationship was not present in mandibular M3. Our results support previous

87 findings suggesting that this biorhythm is sexually dimorphic and provide the first 88 evidence that RP may be one factor influencing sex differences in enamel thickness. 89 Our study also shows that correlations between RP and enamel thickness appear to be most readily detected for tooth types with sufficiently wide ranges of enamel thickness variation, as is the case for maxillary but not mandibular M3. Achieving a sufficient sample size was critical for detecting a sex difference in periodicity.

94 Key Words: Histology; enamel microstructure; growth and development. 
97 Human teeth retain a record of their growth in the form of incremental markings (Fig.

98 1). Retzius lines are one type of marking that are created by ameloblasts during the secretory phase of enamel growth. Ameloblasts periodically alter the way they secrete new matrix, which changes the density, size and shape of rods and inter-rod regions

101 (Weber et al., 1974; Risnes, 1990, 1998; Li and Risnes, 2004). The altered rod 102 morphology becomes visible as Retzius lines when a tooth is prepared as a thin section and viewed under a microscope using transmitted or polarised light. The number of days of enamel secretion between two adjacent Retzius lines is termed Retzius periodicity (RP), or a long period repeat interval.

(a)

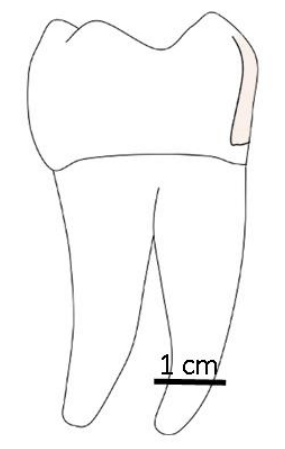

(d)

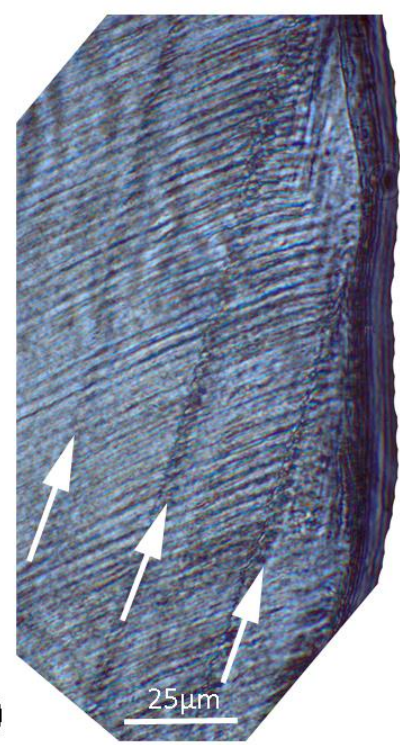

(b)

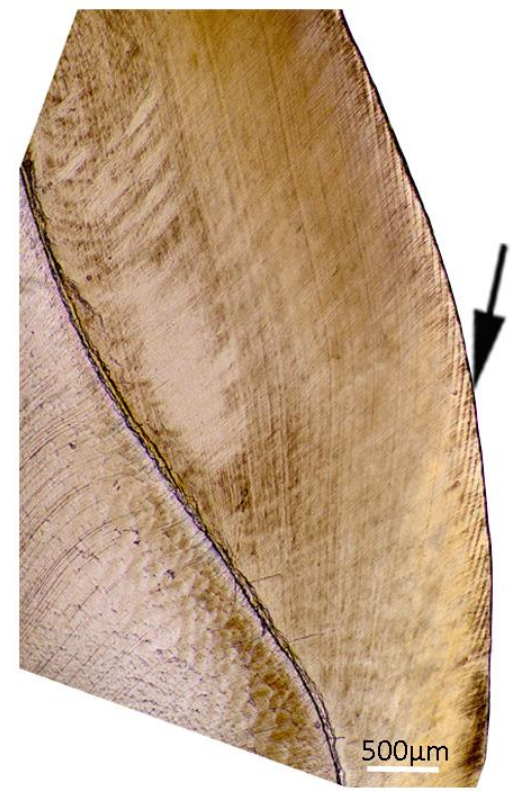

(c)

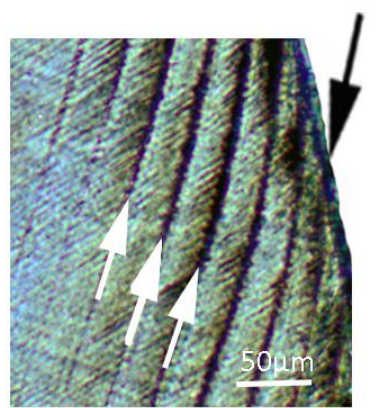

106

107

108

109

110

111

112

113

114

115

116

117

118

119

120

121

122

Fig. 1. Enamel incremental growth markings preserved as Retzius lines.

(a) Illustration of a mandibular permanent third molar and the approximate location of the lateral enamel region on a crown. (b) Thin section of lateral enamel (to the right of the image) imaged at a total (including ocular) magnification of 40x. Black arrows point in the direction of Retzius lines that emerge on the outer lateral enamel surface as perikymata. (c) Retzius lines imaged at 100x magnification and (d) 200x magnification. The 'layers' that are visible in (c) and (d) are an optical phenomenon created by Retzius lines. 
132 FitzGerald, 1998; Reid et al., 1998; Risnes, 1998; Schwartz et al., 2001; Reid and Dean, 133 2006; Reid and Ferrell, 2006; Smith et al., 2007; Mahoney, 2008; Smith, 2008;

134 McFarlane et al., 2014; Nava et al., 2019). A growing body of evidence suggests RP 135 reflects an underlying and newly discovered infradian biorhythm that relates to human 136 skeletal growth. Human RP relates to bone modelling and remodelling (Bromage et al., 137 2009; Mahoney et al., 2016; Pitfield et al., 2019), attained adult stature (Bromage et al., 138 2016a; Mahoney et al., 2018), and molar enamel thickness (Mahoney et al., 2016, 139 2018). The role of this biorhythm for human skeletal sexual dimorphism is poorly 140 understood, and it is unknown if dimorphism in enamel thickness relates to RP.

141 The source of the infradian biorhythm for humans has been investigated but has not 142 been conclusively identified (Gysi, 1939; Newman and Poole, 1993; Appenzeller et al., 143 2005; Bromage et al., 2009, 2016b; also see Kierdorf et al., 2019). It has been suggested 144 that RP may result from an underlying centrally controlled (possibly hypothalamic) 145 metabolic oscillation (Bromage et al., 2009) or the autonomic nervous system that 146 controls cardiac activity (Appenzeller et al., 2005). The underlying process is likely to 147 be complex as there is now a growing body of evidence that points towards a sequence 148 of repeat intervals within individuals rather than a single value (Mahoney et al., 2018). 149 Retzius periodicity changed between deciduous and permanent molars of four children 150 (Mahoney et al., 2017), and recent preliminary analyses revealed RP changed when compared along the human permanent tooth row when molars were compared to incisors (McFarlane et al., 2020). The range of RPs in human deciduous teeth also 153 extends below those of human permanent teeth (Mahoney et al., 2016). In these cases, 154 where RP changes within an individual, in different tooth types that have overlapping 155 formation times, and when this change is unrelated to pathology (Mahoney et al., 2017), 
156 it seems unlikely that a single underlying oscillation can explain the expression of this

157 biorhythm in enamel. It seems increasingly likely that there are more local - even tooth

158 specific - genetic or hormonal regulatory controls underpinning, or having a role, in the

159 timing of these repeat intervals, similar to recent findings for the circadian rhythm in

160 mammals (Ray et al., 2020). Whether or how local control may relate to a broader

161 systemic influence on the infradian biorhythm is unknown. Regardless of the debate

162 about the source, the modal timing is not a unique biorhythm for humans as a near

163 seven-day oscillation has been identified in blood pressure during pregnancy, adult

164 heart rate, and adult core body temperature (Halberg et al., 1964; de la Pena et al., 1989;

165 Otsuka et al., 1994; Ayala and Hermida, 1995; Cornélissen et al., 1996, 2001).

166 Taller adults tend to have lower RPs (Bromage et al., 2016a; Mahoney et al., 2018),

167 meaning their Retzius lines repeat over intervals of fewer days than do those of shorter

168 adults. When considered as a biorhythm, a lower RP has fewer days between Retzius

169 lines representing a faster underlying oscillation. A faster biorhythm has been suggested

170 to result in greater adult height (Bromage et al., 2009). When this hypothetical

171 relationship between RP and height is applied to human sexual dimorphism there is a

172 basis to expect sex differences in the biorhythm. Within any one human population the

173 average adult stature of males will usually be greater compared to that of adult females

174 (e.g., Eveleth, 1975; Hauspie et al., 1985). Thus, following this logic, RP should, on

175 average, be lower in males than it is in females, if RP reflects a faster underlying

176 biorhythm(s) that impacts rates of skeletal growth.

177 Retzius periodicity has been shown in some populations to exhibit the expected sex

178 differences in central tendencies. Permanent molars from South Africans, and canines

179 from England and South Africa, revealed females had higher RPs on average than males

180 (Schwartz et al., 2001; Smith et al., 2007). Other studies of sex differences in RP for

181 samples from North America (Smith et al., 2007) and China (Tan et al., 2017) reported 
182 no differences. The sample size of Chinese adults may not however have been 183 sufficiently large enough to detect a difference. Amongst $n=34$ Chinese adults, the 184 lowest RPs of 6 days were present in males but not females, even though there was no 185 sex difference in their median RP (Tan et al., 2017: their Fig 2).

186 Retzius periodicity has an association with the average enamel thickness (AET) of 187 deciduous second, and permanent first and second human molars (Mahoney et al., 2016, 188 2018). We do not suggest RP has a deterministic effect on enamel thickness. Enamel 189 thickness is determined by the number of active ameloblasts, their secretory life span, 190 and the total period over which these cells are active (Grine and Martin, 1988; Dean, 191 2000). We have previously proposed that RP can relate to some enamel formation 192 processes and enamel thickness in a predictable way for human molars (Mahoney et al., 193 2017). We develop this proposal here (Fig. 2). Deciduous second (Mahoney et al., 194 2017) and permanent first molars (Mahoney et al., 2018) with higher repeat intervals 195 can have a greater distance between adjacent Retzius lines producing thicker enamel 196 layers relative to layers from equivalent regions of molars with lower repeat intervals. 197 Layers become wider because ameloblasts deposit enamel for additional 24-hour 198 periods in crowns with higher repeat intervals without greatly changing the rate at 199 which they secrete new matrix (Mahoney et al., 2017, 2018). Wider layers with higher 200 RP's should result in a molar with a thicker enamel cap but only if the period of time 201 over which the layers accumulate is extended. There is reason to suspect that this can 202 be the case. Retzius periodicity relates to formation time (Mahoney et al., 2016), and 203 formation time relates to enamel thickness (Dean et al., 2001; Mahoney, 2011; Pitfield 204 et al., 2018). Thus, there are clear links between repeat intervals, formation time, and 205 enamel thickness. Taken together these links suggest that when daily secretion rates 206 (DSRs) are held constant higher repeat intervals will relate to thicker enamel caps if 207 crown formation periods or ameloblast lifespans are extended (Mahoney et al., 2017). 


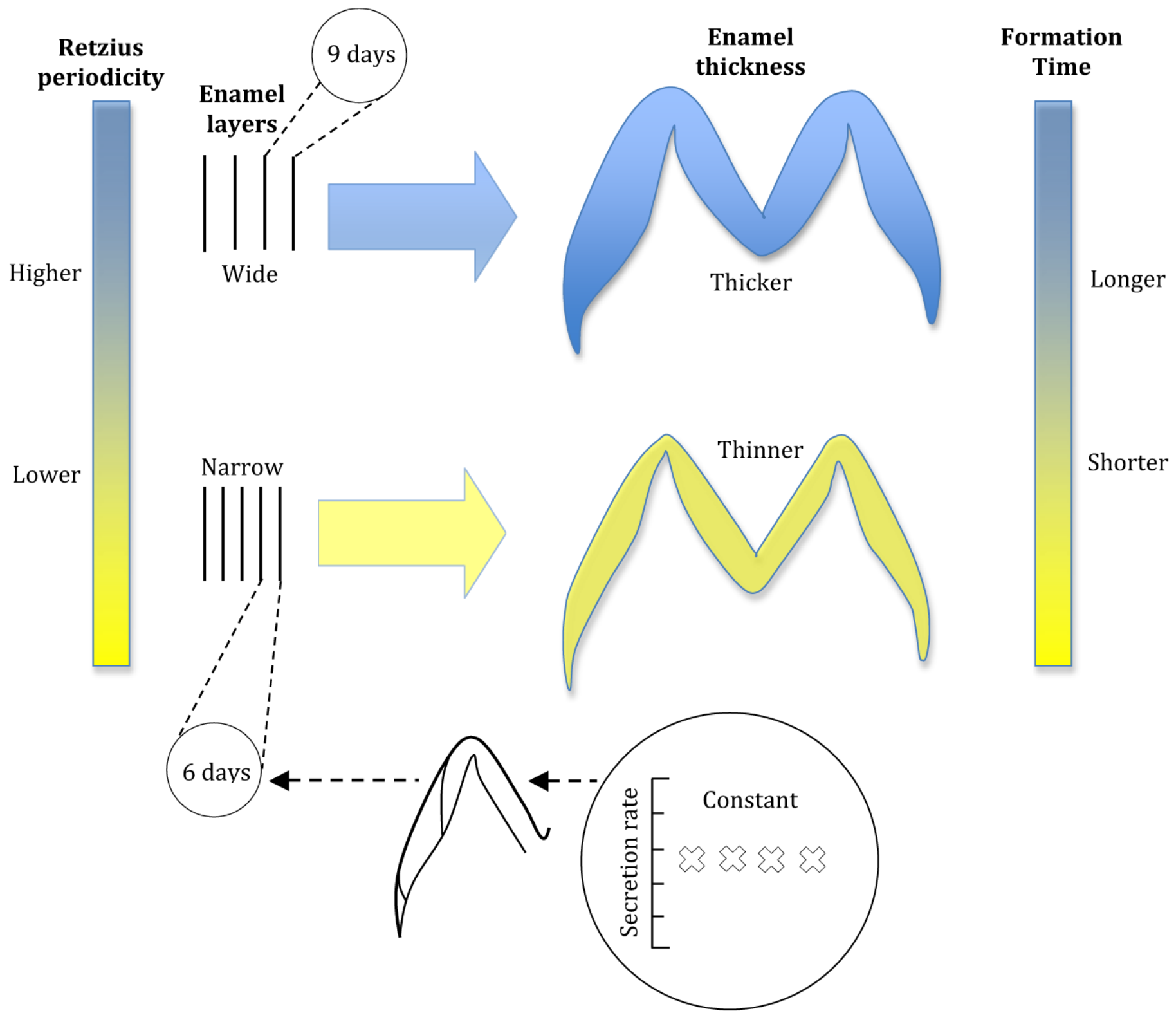

Fig. 2. Model of human molar enamel formation processes incorporating Retzius periodicity. 

second mandibular molars can be greater in females but it is not always the case that it is (Smith et al, 2006; Feeney, 2009; Daubert et al., 2016). Thicker enamel has also been related to a smaller dentin core (and shorter EDJ length) for some female molar types,

231 which can produce a greater AET compared to males (Smith et al., 2006) depending 232 upon the quantity of crown enamel.

When just permanent third molars (M3s) are considered, analyses of thin sectioned mesial cusps and 3D volumetric reconstructions reveal sex differences in dental tissues but there is a different pattern for the upper $\left(\mathrm{M}^{3}\right)$ and lower molar $\left(\mathrm{M}_{3}\right)$. Female $\mathrm{M}^{3} \mathrm{~s}$ can have a greater AET (Smith et al, 2006: their Appendix B). In this case, dimorphism in

237 AET relates to the quantity of crown enamel, not a reduction to the underlying dental components as neither EDJ length nor the quantity or proportion of dentin in $\mathrm{M}^{3}$ differs greatly between the sexes (Smith et al., 2006; see Feeney, 2009: her Table 3.2, 3.3, 3.4). The lower third molar differs to its isomere in that there are usually no sex differences in AET (Stroud et al., 1994; Schwartz and Dean, 2005; Smith et al., 2006; Feeney,

242 2009). Furthermore, the range of enamel thickness values is reduced in $\mathrm{M}_{3}$ compared to 243 the upper molar (Schwartz and Dean, 2005; Smith et al. 2006: their Appendix A). The $244 \mathrm{M}_{3}$ of females also have proportionally less dentin compared to male $\mathrm{M}_{3}$ 's, which 245 occurs in first and second mandibular molars as well (Feeney, 2009; Sorenti et al., 246 2019). It is not clear why enamel and dentin distinguish between males and females in 247 these ways, or if factors thought to contribute to dental sexual dimorphism, such as 248 intra-uterine testosterone and/or Y-chromosome genes, manifest differently in the upper 249 and lower third molars (e.g., Alvesalo et al., 1991; Dempsey et al., 1999; Guatelli250 Steinberg et al., 2008; Ribeiro et al., 2013).

251 1.1. Aims and hypotheses

252 Third molars, available in large numbers through dental extractions provide an 
opportunity to test whether the biorhythm underlying RP is sexually dimorphic. Given that sex differences in enamel thickness have previously been detected in upper but not lower third molars, this tooth type is useful for assessing whether females have both higher periodicities and thicker enamel in $\mathrm{M}^{3}$ but not $\mathrm{M}_{3}$. By focusing on a single tooth type we avoid potential variation in RP along the tooth row (McFarlane et al., 2020). Consistent with average differences in height between the sexes, we test the hypothesis (1) that with a sufficient sample size we will detect a greater average RP in females than males in both upper and lower M3. Also in this study, we hypothesise that if RP has a detectable relationship with enamel thickness, then (2) greater AET should

262 be found in females, especially in upper third molars, in association with their higher 263 average periodicities. More specifically, we predict that if daily enamel secretion rates 264 do not differ between sexes, then sex differences in RP and AET should be present in upper third molars. Such a result would suggest that RP plays a role in sex differences 266 in enamel thickness consistent with the positive association of RP with enamel 267 thickness. (3) Finally, we hypothesise a weaker correlation between RP and AET in 268 lower third molars because of their tighter range of enamel thickness values. Variation 269 is needed for correlation (Bland and Altman, 2001). Based upon prior research we do not expect lower third molars to exhibit sex differences in AET.

\section{2. Material and methods}

272 2.1. Study sample and Ethics

273 Ninety-four permanent third molars were selected from the UCL-Kent dental collection 274 that is composed of permanent teeth collected from dental surgeries in northern Britain 275 between 1964 and 1973. Each tooth had been extracted because of an impending 276 impaction, or an impaction that was current at the time of the extraction. There was no 277 evidence to indicate that enamel growth was abnormal in these molars due to impaction 
278 (see comparisons of DSRs and RP to previous studies in Results and Discussion).

279 Molars that displayed developmental pathology in the form of hypoplasia were

280 excluded, as RP can change within a single crown in response to periods of non-specific

281 stress (Mahoney et al., 2017). The sex of each individual was known but otherwise all

282 teeth were anonymous. Ethical approval for histology research on this sample of teeth

283 was obtained from the UK National Health Service research ethics committee (REC

284 reference: 16/SC/0166; project ID: 203541).

285

286

287 sample was used to compare RP between females $(n=48)$ and males $(n=46)$. We did

- RP was calculated from the lateral enamel of the entire sample of molars. This larger

288 not have measurements of adult height for each individual that provided an M3.

289 Instead, we relied upon the typical difference in sexual dimorphism whereby adult

290 males are on average taller than adult females, which has been reported previously in

291 population standards for adults of northern Britain (Miller et al., 1972).

292

293

294

- We separated out thin sections from females $(n=18)$ and males $(n=17)$ that had clearly preserved and unworn enamel to calculate AET. This smaller sample was used to determine if the biorhythm related to sex differences in enamel thickness.

\subsection{Histology}

298 Thin-sections of M3 were prepared in the

Fig. 3. (a) Enamel incremental cross striations. (b) Black arrows point at

299 Human Osteology Lab, University of Kent, daily cross striations. Prism direction is indicated by the black line

using standard methods (Reid et al., 1998).

301 Teeth were embedded in resin (Buehler

302 EpoxiCure ${ }^{\circledR}$ ) and sectioned through the tip of 303 the cusp and dentin horn using a Buehler

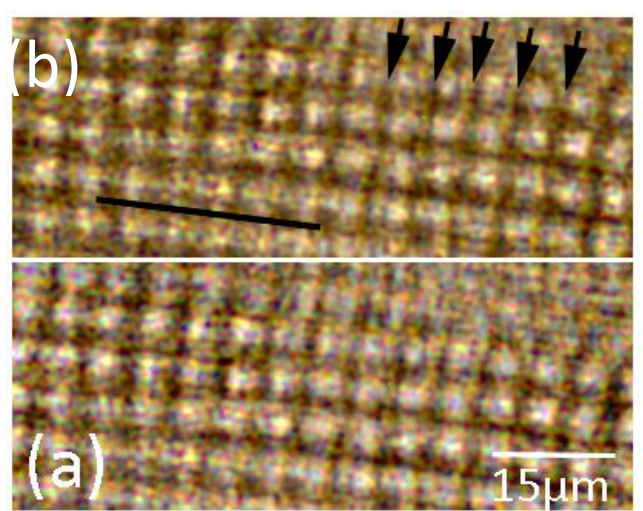


304 Isomet 1000 precision saw. Sections were fixed to glass microscope slides (Evo Stick®)

305 resin), ground with a series of grinding pads (P400, P600, P1200) (Buehler® EcoMet

306300 ), and polished with a $0.3 \mu \mathrm{m}$ aluminium oxide powder to a $60-90 \mu \mathrm{m}$-thick section

307 (Buehler® Micro-Polish II). Each section was cleaned in an ultrasonic bath, dehydrated 308 in $95-100 \%$ ethanol, cleared (Histoclear®), and mounted with a coverslip using a 309 xylene-based mounting medium (DPX®). The thin sections of the teeth were examined 310 using a high-powered microscope (Olympus® BX53) with a mounted microscope 311 camera (Olympus ${ }^{\circledR}$ DP25). Images of the thin sections were obtained and examined in 312 CELL® Live Biology imaging software.

313 Before calculating RP or AET all oblique thin sections were identified and removed 314 from the study. Oblique sections can be easily identified from the morphology of the 315 dentin horn together with the slope of the enamel buccal and lingual surfaces of the 316 functional and guiding cusps. The sample size of $n=94$ is the final sample after these 317 sections had been removed.

318 Retzius periodicity was calculated in lateral enamel from daily cross-striations (Fig.

319 3). Lateral enamel commences as the first Retzius line emerges on the outer enamel 320 surface as a perikymata (Shellis, 1998). Cross-striations appear as light and dark 321 markings along the length of enamel prisms when thin sections of human lateral crown 322 enamel are viewed with transmitted light under a microscope (Boyde, 1989; Nanci, 323 2013). Cross-striations relate to a circadian rhythm in primate enamel (Schour and 324 Poncher, 1937; Okada and Mimura, 1940; Bromage, 1991; Smith, 2006; Zheng et al., $3252011,2013)$.

326 Retzius periodicity was calculated in two ways. The number of daily cross327 striations was counted along a prism between two adjacent Retzius lines in lateral 328 enamel at 200-400x magnifications (includes the ocular magnification). When 329 consecutive cross-striations were not clearly visible between two Retzius lines, RP was 
330 calculated from local daily enamel secretion rates (DSR) divided by prism lengths (e.g., 331 Dean, 1993; Schwartz et al., 2001; Mahoney et al., 2007; Smith, 2008). DSRs were 332 calculated by measuring along a prism across the span of six cross striations, which 333 corresponds to five days of enamel formation (two adjacent cross striations $=24 \mathrm{hrs}$ of 334 enamel secretion), and dividing this measurement by five to get a daily mean DSR. This 335 was repeated six times within the local enamel so that a grand mean DSR could be 336 calculated. Following this, the distance between four to six adjacent Retzius lines was 337 measured, corresponding to three to five repeat intervals respectively, and divided by 338 three or five. This distance between two adjacent Retzius lines was then divided by the 339 grand mean DSR to yield an RP value.

\subsubsection{Inter-observer error test}

342 Three observers recorded Retzius periodicity values in the present study (RP, MO, PM).

343 Inter-observer error tests were conducted by RP, GM, and PM. Values from $n=4$ slides 344 differed in the error test, and these slides were removed from the study giving the final 345 sample size of $n=94$ reported in Section 2.1 above.

2.3. Enamel thickness measurement

The 2D AET in mm was calculated from thin sections of each crown by dividing the area of the enamel cap by the length of the dentin-enamel junction (DEJ), which provides the average straight-line distance between the DEJ and outer enamel surface (Martin, 1983, 1985). None of the thin sections displayed a complex topography of the DEJ, which could artificially increase the AET. 
and Kruskal Wallis test. Associations between log-transformed AET and logtransformed RP were explored with Pearson's $r$.

\section{3. Results}

3.1. Retzius periodicity compared between males and females

361 Mean RP values subdivided by tooth type and sex are shown in Table 1. Corresponding 362 raw data for the entire sample of RP's for this study are available in supplementary 363 Table S1. The median and modal RP for the entire sample was eight days. Retzius 364 periodicity ranged between 7 to 11 days in females (modal of 8 days) and between 6 to 36510 days in males (modal of 7 days; Fig. 4). The mean RP of 8.63 for the entire sample 366 of females was significantly higher when compared to the mean RP of 7.65 for the 367 entire sample of males $(U=621.50 ; p<0.001)$. When the tooth types were subdivided 368 and analysed separately RP was significantly higher in the $\mathrm{M}^{3}$ of females compared to 369 males $(U=89.50 ; p<0.001)$. There was a weaker but still significant difference when $\mathrm{M}_{3}$ was compared between the sexes $(U=229.00 ; p=0.025)$.

Table 1

372 Retzius periodicity in male and female third molars in days.

\begin{tabular}{lccccccc}
\hline Sex & Tooth & Mean $(\mathbf{s d})$ & $\mathbf{9 5 \%}$ CI & min & max & mode & median \\
\hline Combined $(n=94)$ & All M3s & $8.15(1.20)$ & $7.90-8.39$ & 6 & 11 & 8 & 8 \\
Females $(n=48)$ & All M3s & $8.63(1.17)$ & $8.28-8.97$ & 7 & 11 & 8 & 8 \\
Males $(n=46)$ & All M3s & $7.65(1.01)$ & $7.35-7.95$ & 6 & 10 & 7 & 8 \\
Female $(\mathrm{n}=22)$ & $\mathrm{M}^{3}$ & $8.68(0.99)$ & $8.24-9.12$ & 7 & 11 & 8 & 9 \\
Male $(\mathrm{n}=19)$ & $\mathrm{M}^{3}$ & $7.58(1.01)$ & $7.09-8.07$ & 6 & 10 & 7 & 7 \\
Female $(\mathrm{n}=26)$ & $\mathrm{M}_{3}$ & $8.58(1.33)$ & $8.04-9.11$ & 7 & 11 & 8 & 8 \\
Male $(\mathrm{n}=27)$ & $\mathrm{M}_{3}$ & $7.75(1.03)$ & $7.30-8.11$ & 6 & 9 & 7 & 8 \\
\hline
\end{tabular}


Fig. 4. Plot of raw Retzius periodicity values for male and female third molars.

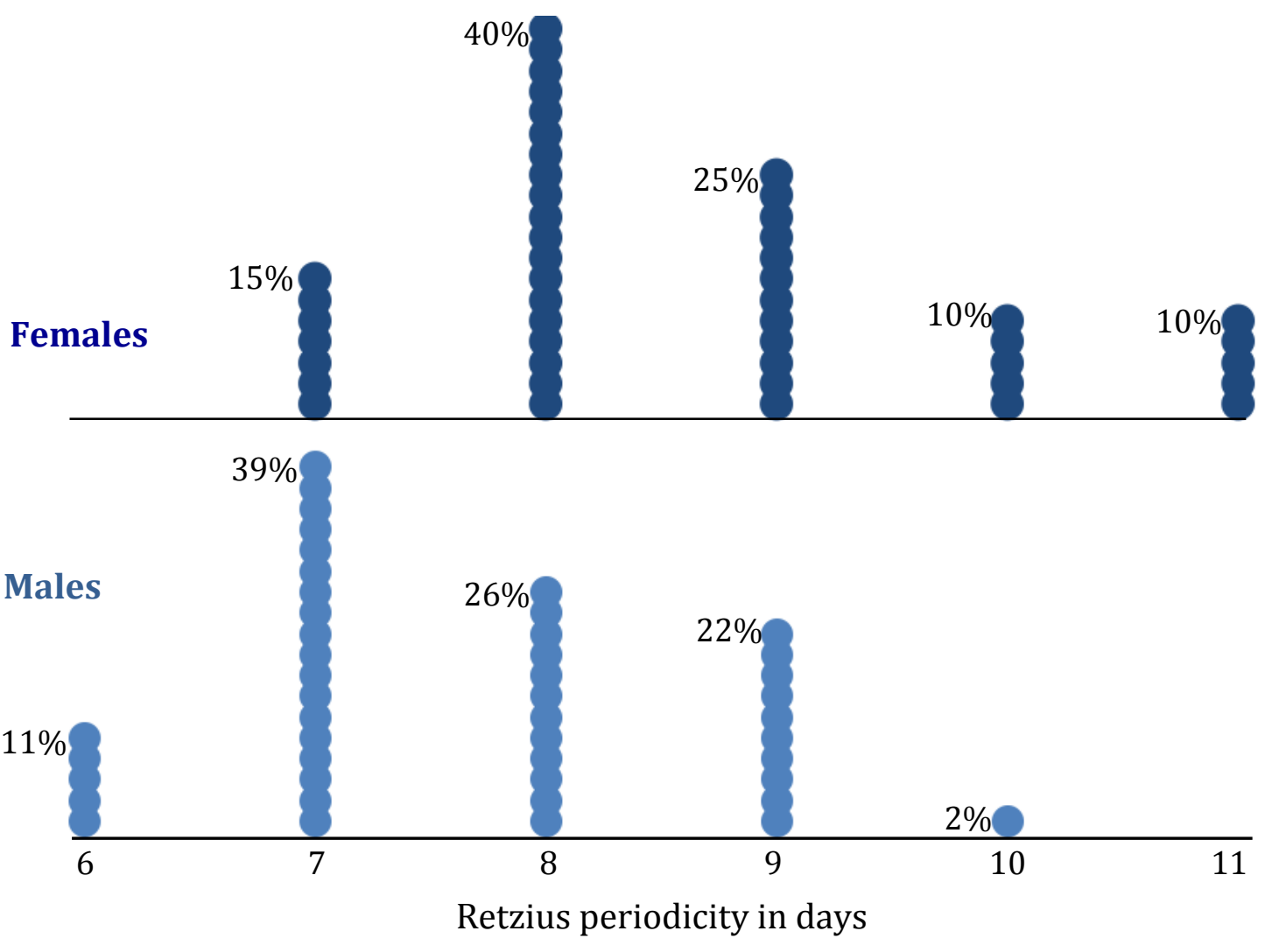

3.2. Enamel thickness compared between males and females

Mean AET subdivided by tooth type and sex are shown in Table 2. Corresponding raw data are available in supplementary Table S2. Sex differences in enamel thickness were apparent in $\mathrm{M}^{3}$ but not $\mathrm{M}_{3}$, which is consistent with previous research for these tooth types (Schwartz and Dean, 2005; Smith et al., 2006). The mean female AET of 1.28 $\mathrm{mm}$ for $\mathrm{M}^{3}$ was significantly greater compared to the male AET of $1.15 \mathrm{~mm}(U=11.00$; $p=0.019$; Fig. 5a). The AET of $\mathrm{M}_{3}$ did not differ significantly between the sexes (Fig. 5b), which had a reduced range of enamel thickness values compared to the upper molars $\left(\mathrm{M}^{3}\right.$ AET range of $0.43 ; \mathrm{M}_{3}$ AET range of 0.32 : see Table $\left.\mathrm{S} 2\right)$. Thicker enamel of $\mathrm{M}^{3}$ compared to $\mathrm{M}_{3}$ has been reported previously (Table 2). 
400 Average (sd) coronal enamel thickness of human third molars in mm.

\begin{tabular}{|c|c|c|c|}
\hline Sex & M3 & AET & Source \\
\hline All & $\mathrm{M}^{3}(n=18)$ & $1.23(0.11)$ & This study \\
\hline All & $\mathrm{M}_{3}(n=18)$ & $1.11(0.07)$ & This study \\
\hline All & $\mathrm{M}^{3}(n=53)$ & 1.38 & Smith et al., $2008^{405}$ \\
\hline All & $\mathrm{M}_{3}(n=45)$ & 1.25 & Smith et al., $2008_{407}^{406}$ \\
\hline & & & 408 \\
\hline Female & $M^{3}(n=12)$ & $1.28(0.10)$ & This study 409 \\
\hline Male & $M^{3}(n=6)$ & $1.15(0.08)$ & This study 410 \\
\hline Female & $M^{3}(n=33)$ & $1.43(0.15)$ & a Smith et al. $2006_{412}^{411}$ \\
\hline Male & $M^{3}(n=11)$ & $1.32(0.08)$ & $\begin{array}{r}\text { aSmith et al. } 2006413 \\
414\end{array}$ \\
\hline Female & $M_{3}(n=7)$ & $1.10(0.07)$ & This study \\
\hline Male & $\mathrm{M}_{3}(\mathrm{n}=11)$ & $1.12(0.08)$ & This study \\
\hline Female & $M_{3}(n=111)$ & $1.20(0.15)$ & ${ }^{\mathrm{b}} \mathrm{Schwartz}$ and Dean, $201 \mathrm{\delta}$. \\
\hline Male & $\mathrm{M}_{3}(\mathrm{n}=33)$ & $1.20(0.15)$ & ${ }^{\mathrm{b} S c h w a r t z}$ and Dean, 2009 \\
\hline Female & $\mathrm{M}_{3}(\mathrm{n}=14)$ & $1.32(0.19)$ & asmith et al. 2006420 \\
\hline Male & $M_{3}(n=4)$ & $1.32(0.04)$ & a Smith et al. $2006_{422}^{421}$ \\
\hline
\end{tabular}

$423 \quad \mathrm{a}=$ Mixed sample of South African, North American, and medieval Denmark, their Appendix B $424 \mathrm{~b}=$ Mixed sample from the UK

425

426

427 Fig. 5. Combined box and scatter plot of average enamel thickness for upper (a) and 428 lower third molars (b). Box plots show the median, inter-quartile and min-max range.

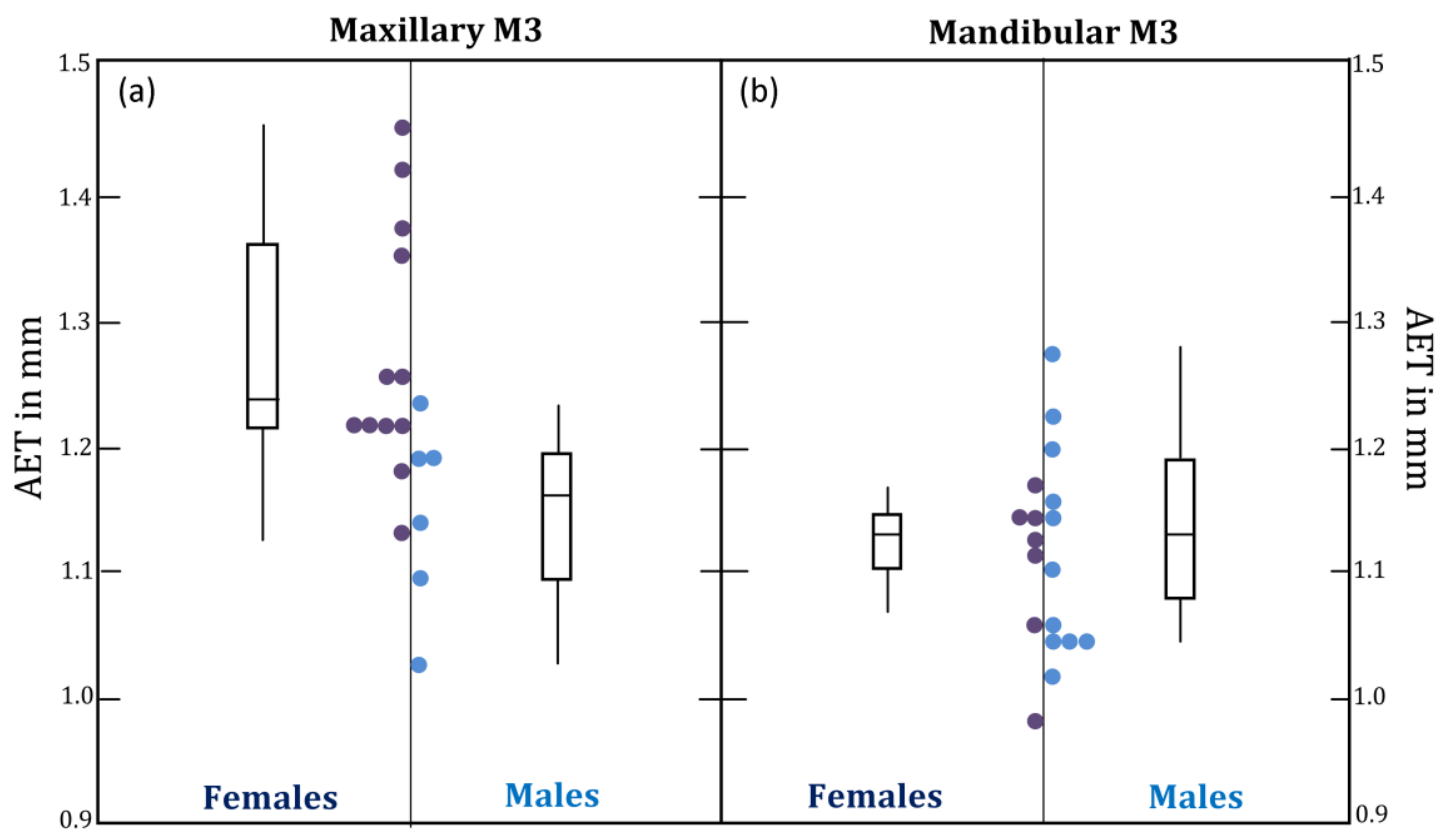


429 3.3. Enamel thickness compared to Retzius periodicity

430 There was a significant correlation between log-AET and log-RP when all molar types

431 were combined $(\mathrm{r}=0.571 ; p<0.001$; Fig. 6a), and a slightly stronger correlation when

432 just $\mathrm{M}^{3}$ was analyzed ( $\mathrm{r}=0.624, p=0.006$; Fig. 6b). The relationship between log-AET

433 and $\log -\mathrm{RP}$ of $\mathrm{M}_{3}$ was much weaker and not significant (Fig. 6c).

434

435

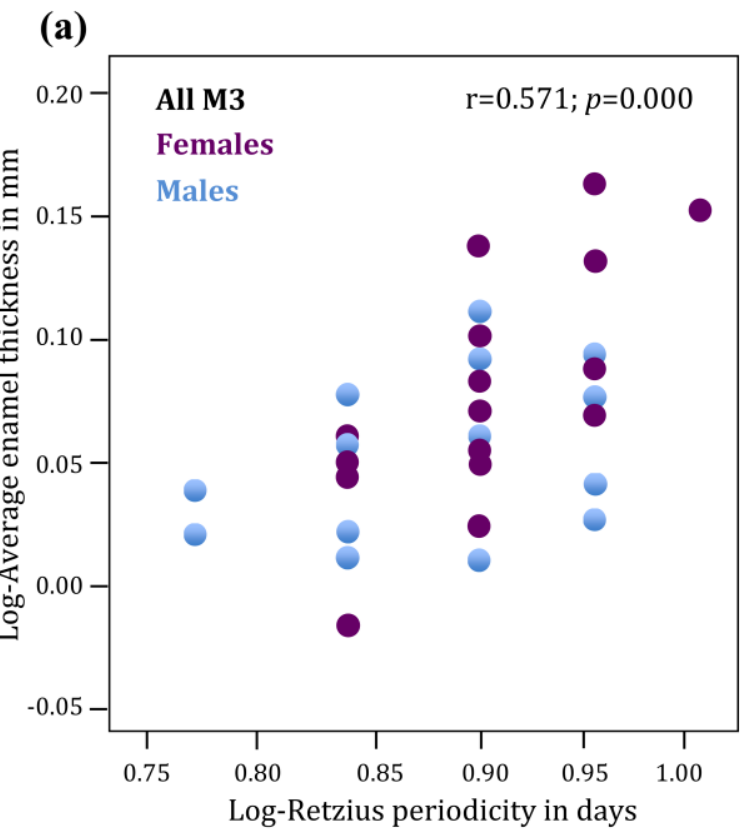

(b)

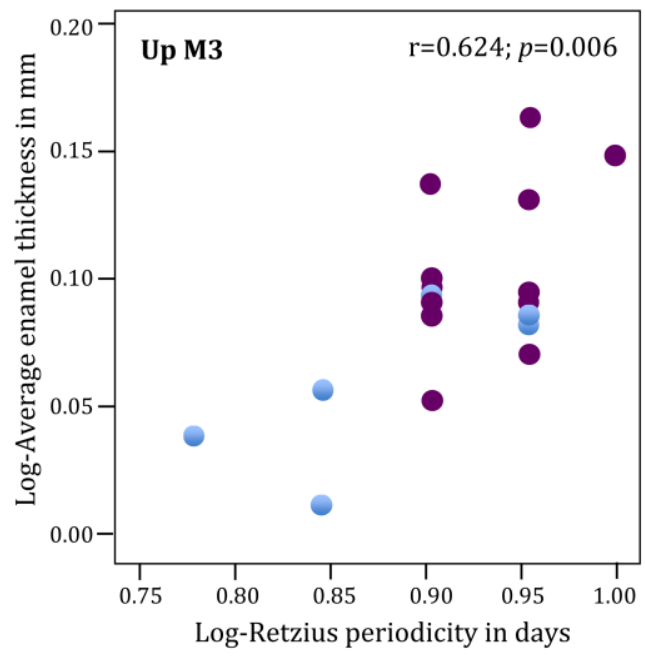

(c)

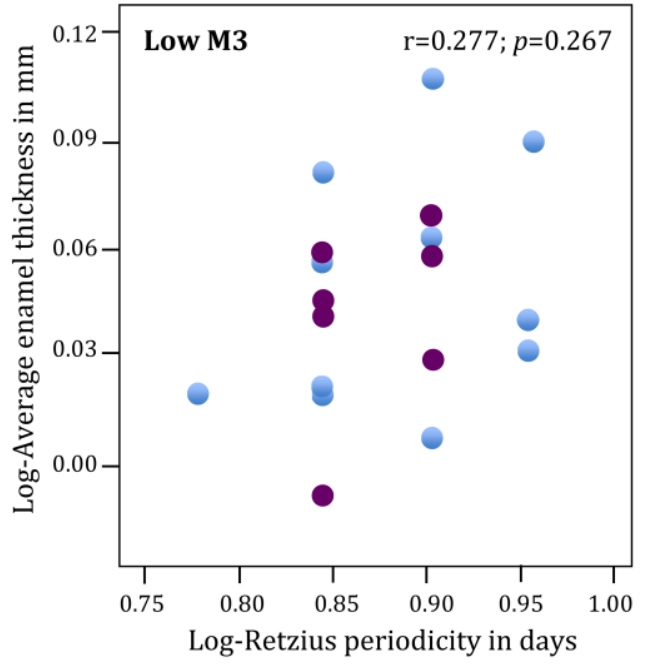

Fig. 6. Scatter plot of log-Retzius periodicity against log-average enamel thickness for (a) all permanent third molars. (b) Permanent maxillary third molars. (c) Permanent mandibular third molars. 
437 3.4. Sex differences in enamel thickness compared to periodicity and secretion rates

438 Retzius periodicity related to sex differences in AET of $\mathrm{M}^{3}$ (Fig. $\mathbf{6 b}$ ). The association 439 between RP and AET was explored further in males and females. When log-AET was 440 compared between periodicities of 7,8 and 9 days (the largest sample size), enamel 441 thickness differed significantly amongst females $\left(x^{2}(2)=7.436 ; p=0.024\right.$; Fig. 7a). 442 Amongst males, log-AET increased from molars that had RP's of 7 days to those that 443 had RPs of 8 or 9 days, but the difference was not significant. The greater increase in 444 enamel thickness for each 'step-up' in RP suggests the link between the biorhythm and 445 AET is stronger for females compared to males.

446 Comparisons of DSRs from the mid cuspal enamel region of permanent 447 maxillary molars indicates that the distribution of DSRs from male and female molars 448 overlaps but does not change greatly between the sexes (Fig. 7b). Males having a 449 slightly lowered mean DSR of $4.08 \mu \mathrm{m} /$ day compared to the mean DSRs of $4.23 \mu \mathrm{m} /$ day 450 of females and the difference in these mean values was not significant. These mean 451 DSRs are similar to those reported previously for mid enamel regions of permanent 452 molars (mean of $4.30 \mu \mathrm{m} \pm 0.50$ and $4.50 \mu \mathrm{m} \pm 0.55$; Beynon et al., 1991; Lacruz and 453 Bromage, 2006). Our finding that DSRs do not differ between males and females is 454 consistent with previous research that has reported no sex related differences in DSRs of human permanent canines (Schwartz et al., 2001), incisors (Aris et al., 2020a), or first molars (Aris et al., 2020b). 
Fig. 7. Retzius periodicity compared to enamel thickness and DSRs. (A) Plot of the variable log-Retzius periodicity against log-average enamel thickness for female and male molars with RPs of 7, 8 and 9 days. (B) Plot of DSRs from the mid-cuspal enamel region of female and male maxillary molars. (C) A composite illustrating that as the biorhythm slows down there is a greater increase in the average enamel thickness of maxillary molars for females compared to males. The line for females is in dark blue; that for males in light blue. Daily enamel secretion rates from maxillary molars change only slightly when compared between the sexes. Box plots show the median, inter-quartile and min-max range.

468

A.

469

470

471

472

473

474

475

476

477

478

479

480

481

482

483

484

485

486

487

488

489

490

491

492

493

494

495

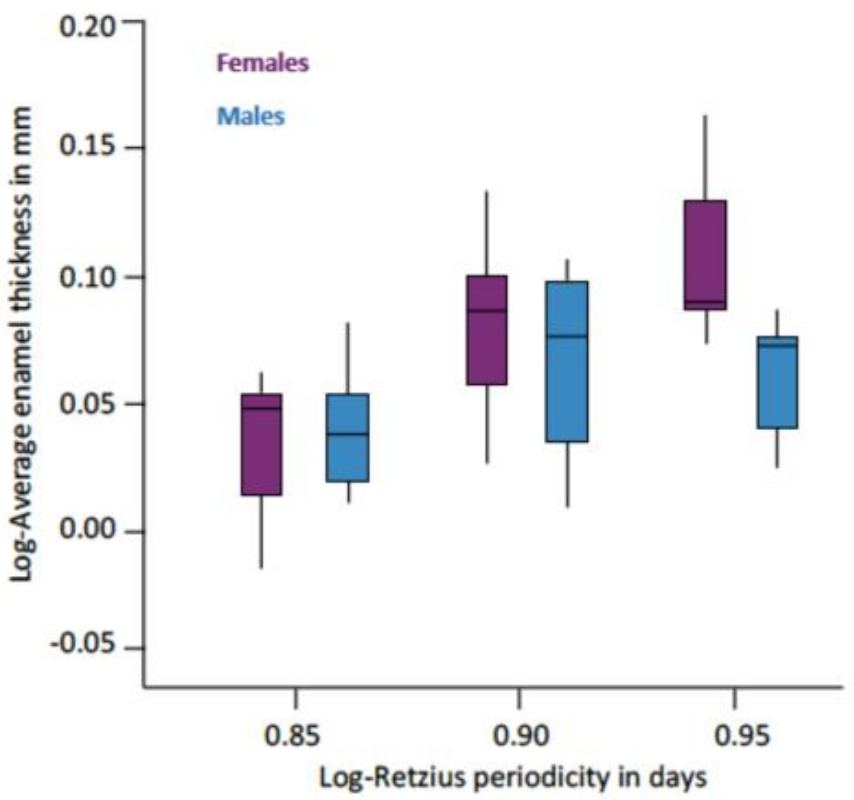

B.

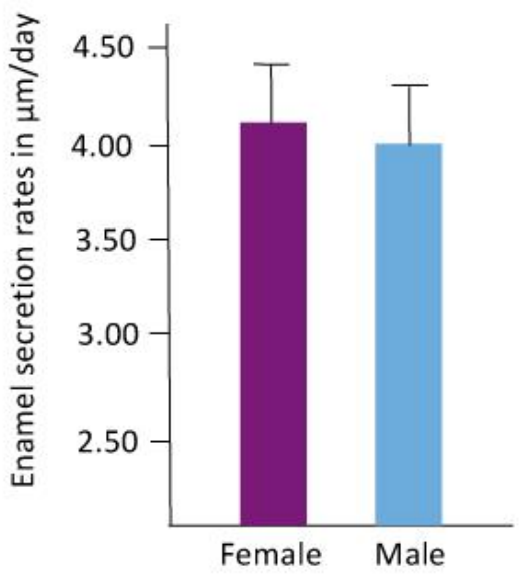

496

C.

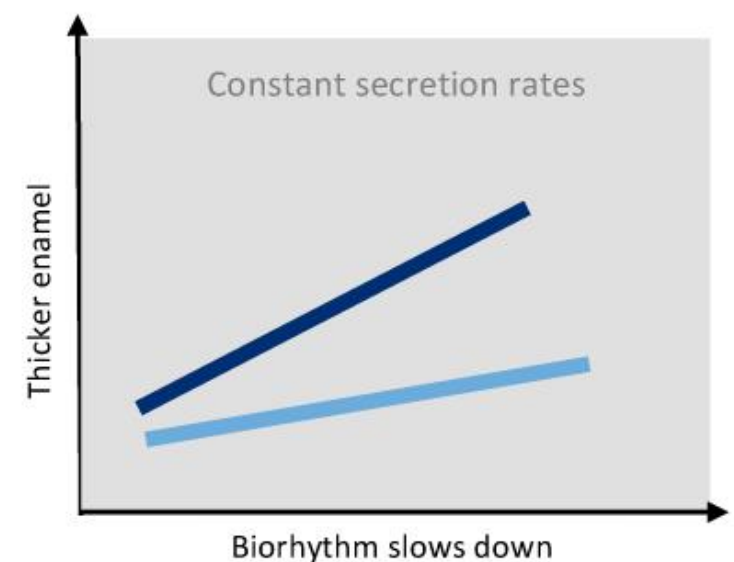




\section{Discussion}

502 We build upon our previous work by showing that RP of human permanent third molars 503 differed between a sample of adult males and females from northern Britain. Adult 504 females had a slower biorhythm as well as thicker maxillary molar enamel when 505 compared to adult males. That the sex with higher average enamel thickness also has a 506 higher average RP is consistent with our finding that within the sexes, RP correlates 507 with average enamel thickness. Our findings provide the first evidence that Retzius 508 periodicity may be associated with sexual dimorphism in human enamel thickness.

509

510 4.1. The timing of Retzius lines

511 The median and modal RP of eight days for the entire sample of M3's from northern 512 Britain is consistent with previous studies of human RP (e.g., Schwartz et al., 2001; 513 Reid and Dean, 2006). Seventy-eight percent of all RP's from adults in northern Britain 514 lay between seven to nine days, which is similar to the distribution of RPs reported by 515 Beynon and Reid (1987), and Smith et al. (2007). We observed a lowermost RP of six 516 days that was present in five males out of the entire sample of 94 adults. We found no 517 evidence of the five-day periodicity observed by Hudda and Bowman (1994) and Hogg 518 et al. (2018).

519

520

\subsection{Sex differences in Retzius periodicity}

521 Females had a higher average RP compared to males (Fig. 4). This finding supports the 522 previously reported relationship between RP and final attained adult stature (Bromage et 523 al., 2016a; Mahoney et al., 2018). There was however a large degree of overlap between 524 the sexes in our data, and the distribution of these values was positively skewed. The 525 overlap by itself is not surprising. Many of the males and females in our sample would 526 likely have been of similar height, which could have contributed to the overlap. 
Differences in RP were greater when $\mathrm{M}^{3}$ was compared between the sexes and weaker in comparisons of $\mathrm{M}_{3}$. These different relationships with the biorhythm are also evident when smaller sub-sets of each tooth type are analysed. Sex differences in RP are

530 apparent in both the larger (Table 1) and smaller sample of $\mathrm{M}^{3}$ s (Fig. 6b), where this 531 relationship is stronger. Sex differences are comparatively weaker in the larger sample 532 of the lower molar (Table 1) and this link disappears in the smaller sample of this tooth 533 type (Fig. 6c). This means that fundamental methodological choices are a factor when 534 searching for dimorphism in RP. Sample size is one factor because of the large degree 535 of overlap between males and females (Fig. 4). Tooth type is clearly another. Perhaps it 536 is only possible to detect consistent sex differences in RP in teeth that also display sex 537 differences in AET, as it may be these teeth that are most responsive to the underlying 538 oscillation (see Sections 4.4-5 below).

539

540 4.3. Retzius periodicity related to enamel thickness

541 Correlation between AET and RP is consistent with our previously reported findings for 542 human molars (Mahoney et al., 2016, 2018). The correlation was strongest when just $543 \mathrm{M}^{3}$ s were considered and was weaker and non-significant for $\mathrm{M}_{3}$. Our data reveal a 544 greater range of enamel thickness values $(0.43 \mathrm{~mm})$ and a higher standard deviation 545 (0.11) for the upper molar compared to the range of AETs $(0.32 \mathrm{~mm})$ and standard 546 deviation (0.07) for the lower molar. A greater range in $\mathrm{M}^{3}$ AET has been reported 547 previously (Smith et al., 2006), and also suggests a reason for the difference in the 548 strength of the correlation coefficients for upper and lower M3's. Lower third molars 549 display a weaker correlation between RP and AET in part because of their reduced 550 range of enamel thickness values. Limited variation in male AET values (range=0.26; $551 \mathrm{sd}=0.08$ ) compared to females (range=0.49; $\mathrm{sd}=0.12$ ) may also explain why a 'step-up' 552 in periodicity led to a greater effect on the AET of female molars (Fig. 7a). 

much stronger link to AET with higher periodicities. This makes sense as upper molars have thicker enamel that takes longer to form compared to $\mathrm{M}_{3}$ (Table 2; Reid and Dean, 2006). Thus, an upper $\mathrm{M}^{3}$ with a high RP of 9 or 10 days will have a greater AET

557 because the thickened enamel layers will have more time to accumulate compared to a 558 lower molar (see Fig. 2). By comparison, an $\mathrm{M}_{3}$ with an RP of 9 or 10 days will have a 559 lower AET because the same thickened enamel layers will have had relatively less time 560 to accumulate producing a smaller change in AET. The effect of an increased 561 periodicity is therefore more pronounced on the enamel thickness of the upper molar 562 because of the relatively extended growth period, leading to a stronger correlation 563 between RP and AET for $\mathrm{M}^{3}$. This may explain why the lower molars with a shorter 564 formation time have a more restricted range of AET values. Others have also noted 565 developmental differences between maxillary and mandibular teeth (McCollum and 566 Sharpe 2001; Modesto-Mata et al. 2020).

567 Figures $6 \mathrm{a}$ and $6 \mathrm{~b}$ illustrate that within the sexes, females with higher RPs and 568 thicker enamel occupy the upper right side of the graph, though with overlap with males 569 in the middle. It is clear that RP relates to enamel thickness in a predictable way for $\mathrm{M}^{3} \mathrm{~s}$ 570 and this relationship is strongest for females. We do not suggest RP is the only factor 571 relating to thicker enamel. A reduction in the overall size of the dentin core along the 572 molar row leads to greater AET and relatively thicker enamel on M3 compared to the 573 first molar (Grine, 2005; Smith et al., 2008). This was not the case for our samples, as 574 there was only a weak non-significant correlation between AET and the size of the 575 dentin core within maxillary third molars $(\mathrm{r}=0.297, p=0.099)$ or when just the female 576 M3s are considered $(r=0.494, p=0.176)$. Third molars with thicker enamel did not have 577 a smaller dentin core. Thus, the relationship between these dental tissues for M3 of 
578 females differs to the mechanism that produces a gradient of enamel thickness along the 579 molar row.

580

581 4.5. Sex differences in enamel thickness related to RP and DSRs

582 Retzius periodicity was associated with a sex difference in enamel thickness of $\mathrm{M}^{3}$ (Fig.

583 6b). There was a weaker link between and RP and AET in the lower third molar that did 584 not distinguish between males and females (Fig. 6c). The fact that RP co-varies with 585 sex differences in enamel thickness suggests the 'slowed oscillation' that produces 'thickened layers' is also integrated into formation processes that lead to sexual 587 dimorphism in enamel thickness. The greater AET of female $\mathrm{M}^{3}$ 's is not achieved by 588 altering the daily amount of enamel produced by secretory ameloblasts (Fig. 7b), which 589 is the same as human permanent canines (Schwartz et al., 2001). There is reason to 590 think therefore that if males and females have similar DSRs, and females with higher 591 periodicities are taking longer to form their $\mathrm{M}^{3}$, they will build up more enamel in their 592 molar crown than males. Retzius periodicity relates to formation time (Mahoney et al., 593 2016) and formation time relates to enamel thickness (Dean et al., 2001; Mahoney, 594 2011; Pitfield et al., 2018). Given that our data show sex differences in both periodicity 595 and enamel thickness of $\mathrm{M}^{3} \mathrm{~s}$ it would seem likely that, on average, female molars will 596 form over a longer period of time. Smaller dentin cores and shorter EDJ lengths do not 597 explain the sex difference in AET in our samples $\left(\mathrm{M}^{3}\right.$ female EDJ length $=20.77 \mathrm{~mm}$, male $=20.99 \mathrm{~mm}$ ), which is consistent with prior research for this tooth type (Smith et al, 2006: Appendix B; Feeney, 2009: Table 3.2-3.3). Future studies might explore 600 dimorphism in formation time related to RP.

601 There is now a growing body of evidence that suggests circadian and infradian 602 biorhythms do not connect to human hard tissue formation in the same way. First, we have shown that the infradian rhythm does not relate to the amount of enamel secreted 
604 by ameloblasts over a 24-hour period in humans (Mahoney et al., 2017). As molar long 605 period repeat intervals increase enamel layers became wider but ameloblasts do not 606 secrete more or less enamel, which suggest the two underlying biorhythms relate to 607 incremental enamel formation processes in different ways. Second, data in the present 608 study are consistent with others that have reported the circadian rhythm underlying the 609 production of daily cross-striations in human enamel is not sexually dimorphic 610 (Schwartz et al., 2010; Ariz et al., 2020a,b). Our data provide evidence that the 611 infradian rhythm underlying Retzius lines is sexually dimorphic. Third, there are now 612 clear indications in the literature that one individual can have a sequence of infradian 613 repeat intervals. The fact that one individual can have multiple RPs in different teeth 614 that form at the same time is unlike the timing of the circadian rhythm in human enamel. The circadian rhythm is entrained by the 24-hour light-dark cycle, and remains synchronised to this rhythm unless it is removed from this environment and is free running. The effect of environment on RP is currently unknown. Taken together, these 618 data point towards fundamental differences in the infradian and circadian biorhythms 619 within humans, and the ways in which they connect to hard tissue formation.

620

\section{5. Conclusions}

622 Long period markings in enamel have fascinated dental morphologists for more than a 623 century as they have eluded explanation. Our study explored their relationship to 624 aspects of human skeletal dimorphism. We have shown that in a sample of $n=94$ 625 permanent third molars from Britain there was a sex difference in the average timing of 626 these markings that related to the thicker maxillary molar enamel of females. Our 627 findings lend support to the growing body of evidence that points towards a 628 biorhythm(s) that underpins these markings in enamel and relates to human skeletal 629 growth and morphology. 


\section{Funding}

631 This study was undertaken as part of The Biorhythm of Childhood Growth project 632 funded by The Leverhulme Trust (grant number RPG-2018-226). The Royal Society 633 provided an equipment grant (grant number RG110435). This study was supported by 634 NSF Graduate Research Fellowship (program grant number DGE-1343012) to Mackie 635 O'Hara. Any opinions, findings, and conclusions or recommendations expressed in this 636 material are those of the authors and do not necessarily reflect the views of the National 637 Science Foundation.

638

\section{Declaration of Competing Interest}

640 The authors declare that they have no known competing financial interests or personal 641 relationships that could have appeared to influence the work reported in this paper.

642

643

\section{Supplementary data}

645 Tables S1 and S2 contains the raw RP and AET data.

646

647

648

649

650

651

652

653

654

655

656

657

658

659 
661

662

663

664

665

666

667

668

669

670

671

672

673

674

675

676

677

678

679

680

681

682

683

684

685

686

687

688

689

690

691

692

693

694

695

696

697

698

699

700

701

702

703

704

705

706

707

708

709

710

\section{References}

Alvesalo, L., Tammisalo, E., Townsend G., 1991. Upper central incisor and canine tooth crown size in 47,XXY males. J. Dent. Res. 70, 1057-1060.

Appenzeller, O., Gungab, H.C., Quallsc, C., Furland, R., Portae, A., Lucas, S.G., Heckert, A.B., Kirsch, K., Costa-Junqueirag, M.A., Guillén, S.E., Sanderi, M.., Schneider, T., Blottner, B., 2005. A hypothesis: autonomic rhythms are reflected in growth lines of teeth in humans and extinct archosaurs. Auto. Neurosci: Basic. Clin. $117,115-119$

Aris, C., Mahoney, P., Deter, C. 2020a. Enamel growth rates of anterior teeth in males and females from modern and ancient British populations. American Journal of Physical Anthropology.

Aris, C., Mahoney, P., O'Hara, M. C., Deter, C. 2020b. Enamel thickness and growth rates in modern human permanent first molars over a 2000 year period in Britain. American Journal of Physical Anthropology.

Ayala, D.E., Hermida, R., 1995. Multi-frequency infradian variation in blood pressure during and after pregnancy. Chronobiol. Int. 12, 333-43.

Beynon, A.D., Reid, D.J., 1987. Relationships between perikymata counts and crown formation times in the human permanent dentition. J. Dent. Res. 66, 889-890.

Beynon, A.D., Dean, M.C., Reid, D.J., 1991. On thick and thin enamel. Am. J. Phys.Anth. 86, 295-309.

Boyde, A., 1989. Enamel. In: Oksche, A., Vollrath, L. (Eds.), Handbook of Microscopic Anatomy vol V/6 Teeth. Springer, Berlin, pp. 309-473.

Bromage, T.G., 1991. Enamel incremental periodicity in the pig-tailed macaque: a polychrome fluorescent labeling study of dental hard tissues. Am. J. Phys. Anthropol. 86, 205-214

Bromage, T.G., Lacruz, R.S., Hogg, R., Goldman, H.M., McFarlin, S.C., Warshaw, J., Dirks, W., Perez-Ochoa, A., Smolyar, I., Enlow, D.H., Boyde, A., 2009. Lamellar bone is an incremental tissue reconciling enamel rhythms, body size, and organismal life history. Calcif. Tiss. Int. 84, 388-404.

Bromage, T.G., Hogg RT., Lacruz, R.S., Hou, C., 2012. Primate enamel evinces long period biological timing and regulation of life history. J. Theor. Biol. 305, 131-144.

Bromage, T.G., Juwayeyic, Y.M., Katrisa, J.A., Gomez, S., Ovsiya, O., Goldstein, J., Janal, M.N., Hu, B., Schrenk, F., 2016a. The scaling of human osteocyte lacuna density with body size and metabolism. C. R. Palevol. 15, 32-39.

Bromage, T.G., Idaghdour, Y., Lacruz, R.S., Crenshaw, T.D., Ovsiy, O., Rotter, B., Hoffmeier, K., Schrenk, F., 2016b. The swine plasma metabolome chronicles 'many days' biological timing and functions linked to growth. PLoS One 11, e145919. 
711 Cornélissen, G., Halberg, F., Wendt, H.W., Bingham, C., Sothern, R.B., Haus, E., 712 Kleitman, E., Kleitman, N., Revilla, M.A., Revilla, M., Breus, T.K., Pimenov. K., 713 Grigoriev, A.E., Mitish, M.D., Yatsyk, G.V., Syutkina, E.V., 1996. Resonance of 714 about-weekly human heart rate rhythm with solar activity change. Biologia. (Bratisl). $715 \quad 51,749-56$.

Cornélissen, G., Engebretson, M., Johnson, D., Otsuka, K., Burioka, N., Posch, J., Halberg, F., 2001. The week, inherited in neonatal human twins, found also in geomagnetic pulsations in isolated Antarctica. Biomed. Pharmacother. 55, 32-50.

Daubert, D.M., Kelley, J.L., Udod, Y.G., Harbor, C., Kleist, C.G., Furman, IK., Tikonov, I.N., Swanson WJ., Roberts, FA., 2016 Human enamel thickness and ENAM polymorphism. Int. J. Oral. Sci. 8(2): 93-97.

Dean, M.C., 1993. Daily rates of dentine formation in macaque tooth roots. Int. J. Osteoarchaeol. 3, 199-206.

Dean, M.C., 2000. Progress in understanding hominoid dental development. J Anat 197, 77-101.

de la Pena., S.S., Halberg., F., Galvagno, A., Montalbini, M., Follini, S., Wu, J., Degioanni, J., Kutyna, F., Hillman, D.C., Kawabata, Y., Cornelissen, G., 1989. Circadian and circaseptan (about 7-day) free-running physiologic rhythms of a woman in social isolation. Proc IEEE Symp Comp Med Sys. pp 273-278.

Dempsey, P., Townsend, G.C., Richards, L.C., 1999. Increased crown size in females with twin brothers: evidence for hormonal diffusion between human twins in utero. Am. J. Hum. Biol. 11, 577-586.

Eveleth, P.B., 1975. Differences between ethnic groups in sex dimorphism of adult height. Ann. Hum. Biol. 2, 35-39. tissue distribution in human molars. PhD Thesis. Ohio State University.

FitzGerald, C.M., 1998. Do enamel microstructures have regular time dependency? Conclusions from the literature and a large scale study. J. Hum. Evol. 35, 371-386.

Fukuhara, T., 1959. Comparative anatomical studies of the growth lines in the enamel of mammalian teeth. Acta. Anat. Nipp. 34, 322-332.

Grine, F.E., Martin, L.B., 1988. Enamel thickness and development in Australopithecus and Paranthropus. In: Grine, FE. (Ed.), The evolutionary history of the robust australopithecines. New York: Aldyne de Gruiter, pp. 3-42.

Grine, F.E., 2005. Enamel thickness of deciduous and permanent molars in modern 758 
760 hormone concentrations: Another look at the development of sexual dimorphism. Am. J. Phys. Anthropol. 137, 324-333.

Gysi, A., 1939. Metabolism in adult enamel. Dent. Digest. 37, 661-668.

Halberg, F., Diffley, M., Stein, M., Panofsky, H., Adkins, G., 1964. Computer techniques in the study of biological rhythms. Ann. N. Y. Acad. Sci. 115, 695-720.

Hauspie, R., Das, S.R., Preece, M.A., Tanner, J.M., Susanne, C., 1985. Decomposition of sexual dimorphism in adult size of height, sitting height, shoulder width and hip width in a British and West Bengal sample. In: Ghesquire, J., Martin, R.D., Newcombe, F. (Eds.), Human sexual dimorphism. Taylor and Frances: London, pp. 207-215.

Hogg, R.T., Hu, B., Bromage, T.G., 2018. Histology of dental long-period biorhythms in Canis familiaris. J. Anat. 233, 618-624.

Huda, T., Bowman, J.E., 1994. Variation in cross-striation number between striae in an archaeological population. Int. J. Osteo. Arch. 4, 49-52.

Kierdorf, H., Breuer, F., Witzel, C., Kierdorf., U., 2019. Pig enamel revisited Incremental markings in enamel of wild boars and domestic pigs. J. Struct. Biol. 205, 48-59.

Lacruz, R.S., Bromage, T.G., 2006. Appositional enamel growth in molars of South African fossil hominoids. J. Anat. 209, 13-20.

Li, C., Risnes, S., 2004. SEM observations of Retzius lines and prism cross-striations in human dental enamel after different acid etching regimes. Arch. Oral. Biol. 49, 45-52.

Mahoney, P., 2008. Intraspecific variation in M1 enamel development in modern humans: implications for human evolution. J. Hum. Evol. 55: 130-146

Mahoney, P., Smith, T.M., Schwartz, G.T., Dean, M.C., Kelley, J., 2007. Molar crown formation in the late Miocene Asian hominoids, Sivapithecus parvada and Sivapithecus indicus. J. Hum. Evol. 53, 61-68.

Mahoney, P., Miszkiewicz, J., Pitfield, R., Schlecht, S., Deter, C., Guatelli-Steinberg, D. 2016. Biorhythms, deciduous enamel thickness, and primary bone growth in modern human children: a test of the Havers-Halberg Oscillation hypothesis. J. Anat. 228, 919-928.

Mahoney, P., Miszkiewicz, J., Pitfield, R., Deter, C., and Guatelli-Steinberg, D. 2017. Enamel biorhythms of humans and great apes: the Havers-Halberg Oscillation hypothesis reconsidered. J. Anat. 230, 272-281.

Mahoney, P., Miszkiewicz, J., Chapple, S., Le Luyer, M., Schlecht, S., Stewart, T., Griffiths, R., Deter, C., Guatelli-Steinberg, D. 2018. The biorhythm of human skeletal 
809

810

811

812

813

814

815

816

817

818

819

820

821

822

823

824

825

826

827

828

829

830

831

832

833

834

835

836

837

838

839

840

841

842

843

844

845

846

847

848

849

850

851

852

853

854

855

856

857
Martin, L.B., 1983. Relationships of the later Miocene Hominoidea. Ph.D. Dissertation, University College London.

Martin, L.B., 1985. Significance of enamel thickness in hominoid evolution. Nature 314, 260-263.

McCollum, Melanie A., and Paul T. Sharpe. 2001. "Developmental Genetics and Early Hominid Craniodental Evolution.” BioEssays 23 (6): 481-93.

McFarlane, G., Guatelli-Steinberg, D., Loch, C., White, S., Pitfield, R., Bayle, P., Floyd, B., Mahoney, P. Retzius lines: an inconstant biorhythm in human teeth Am J Phys Anth 171, 179-179

Miller, F.J.W., Billewicz, W.Z., Thomson, A.M. 1972. Growth from birth to adult life of 442 Newcastle Upon Tyne children. Brit. J. Prev. Soc. Med. 26, 224-230.

Modesto-Mata, Mario, M. Christopher Dean, Rodrigo S. Lacruz, Timothy G. Bromage, Cecilia García-Campos, Marina Martínez de Pinillos, Laura Martín-Francés, et al. 2020. Short and Long Period Growth Markers of Enamel Formation Distinguish European Pleistocene Hominins. Scientific Reports 10 (1): 4665.

Nanci, A., 2013. Enamel. In: Nanci, A. (Ed.), Ten Cate's Oral Histology, Development, Structure, and Function, eighth edition. Elsevier, St. Louis, pp. 122-164.

Nava, A., Frayer, D.W., Bondioli, L., 2019. Longitudinal analysis of the microscopic dental enamel defects of children in the Imperial Roman community of Portus Romae (necropolis of Isola Sacra, 2nd to 4th century CE, Italy). J. Arch. Sci. Rep. 23, 406415.

Newman, H., Poole, D., 1993. Dental enamel growth. J. R. Soc. Med. 86, 61.

Okada, M., Mimura, T., 1940. Zur Physiologie und Pharmakologie der Hartgewebe. III. Mitteilung: Über die Genese der rhythmischen Streifenbildung der harten Zahngewebe. Jpn. J. Med. Sci IV Pharmacol. 13, 92-95.

Otsuka, K., Cornélissen, G., Halberg, F., 1994. Broad scope of a newly developed actometer in chronobiology, particularly chronocardiology. Chronobio. 21, 251-64.

Pitfield R, Deter C, Mahoney P. 2018. Thick enamel, thin bone: a common link in human juvenile hard tissue growth? American Journal of Physical Anthropology 165 (S66): 209.

Pitfield, R., Miszkiewicz, J.J., Mahoney, P., 2019. Microscopic markers of an infradian biorhythm in human juvenile ribs. BONE. 120, 403-410.

Ray, S., Valekunja, UK., Stangherlin, A., Howell, SA., Snijders, AP., Damodaran, G., Reddy, AK. 2020. Circadian rhythms in the absence of the clock gene Bmal1. Science. 367: 6497. 
Reid, D.J., Beynon, A.D., Ramirez Rozzi, F.V., 1998. Histological reconstruction of Hum. Evol. 35, 463-477.

Reid, D.J., Dean, M.C., 2006. Variation in modern human enamel formation times. J. Hum. Evol. 50, 329-346.

Reid, DJ., Ferrell, R.J. 2006. "The Relationship between Number of Striae of Retzius and Their Periodicity in Imbricational Enamel Formation." Journal of Human Evolution 50 (2): 195-202

Retzius, A. 1837. Bemerkungen über den inneren Bau der Zähne, mit besonderer Rücksicht auf dem in Zahnknochen vorkommenden Röhrenbau. (Müllers). Arch. Anat. Physiol. 486-566

Ribeiro, D.C., Brook, A.H., Hughes, T.E., Sampson, W.J., Townsend, G.C., 2013. Intrauterine hormone effects on tooth dimensions. J. Dent. Res. 92, 425-413.

Risnes, S., 1990. Structural characteristics of staircase-type retzius lines in human dental enamel analyzed by scanning electron microscopy. Anat. Rec. 226, 135-146.

Risnes S., 1998. Growth tracks in dental enamel. J. Hum. Evol. 35, 331-350.

Saunders, S.R., Chan, A.H.W., Kahlon, B., Kluge, H.F., FitzGerald, C.M., 2007. Sexual dimorphism of the dental tissues in human permanent mandibular canines and third premolars. 133, 735-40

Schour, I., Poncher, H.G., 1937. Rate of apposition of enamel and dentin, measured by the effect of acute fluorosis. Am. J. Dis. Child. 54, 757-776.

Schwartz, G.T., Dean, M.C., 2001. Ontogeny of canine dimorphism in extant hominoids. Am. J. Phys. 115, 269-283.

Schwartz, G.T., Reid, D.J., Dean, C., 2001. Developmental aspects of sexual dimorphism in hominoid canines. Int. J. Primatol. 22, 837-860.

Schwartz, G.T., Dean, M.C. 2005. Sexual dimorphism in modern human permanent teeth. Am. J. Phys. Anthropol. 128(2): 312-7.

Shellis, R.P., 1998. Utilization of periodic markings in enamel to obtain information on tooth growth. J. Hum. Evol. 35, 387-400.

Smith, T., 2006. Experimental determination of the periodicity of incremental features in enamel. J. Anat. 208, 99-113.

Smith, T.M., 2008. Incremental dental development: methods and applications in hominoid evolutionary studies. J. Hum. Evol. 54, 205-224/

Smith, T.M., Olejniczak, A.J., Reid, D.J., Ferrell, R.J., Hublin, J.J., 2006. Modern 
human molar enamel thickness and enamel-dentin junction shape. Arch. Oral. Biol.

$90951,974-995$.

910

911

912

913

914

915

916

917

918

919

920

921

922

923

924

925

926

927

928

929

930

931

932

933

934
Smith, T.M., Reid, D.J., Dean, M.C., Olejniczak, A.J., Ferrell, R.J., Martin, L.B., 2007. New perspectives on chimpanzee and human molar crown development. In: Bailey, S,E., Hublin, J.J. (Eds.), Dental perspectives on human evolution: state of the art research in dental paleoanthropology. Dordrecht: Springer. pp 177-192.

Smith, T. M., Olejniczak, AJ., Reh, S., Reid, D.J., Hublin, JJ. 2008. Brief Communication: Enamel thickness trends in the dental arcade of humans and chimpanzees. Am. J. Phys. Anth. 136: 237-41

Stroud, JL., Buschang, PH, Goaz, PW. 1994. Sexual dimorphism in mesiodistal dentin and enamel thickness. Dentomaxillofac. Radiol. 23, 169-71

Tan, S.H.X., Sim, Y.F., Hsu, C.S., 2017. Difference in striae periodicity of Heilongjiang and Singaporean Chinese Teeth. Front. Physiol. 8, 442.

Weber, D.F., Eisenmann, P.L., Glick, P.L., 1974. Light and electron microscopic studies of Retzius lines in human cervical enamel. Am. J. Anat. 141, 91-104.

Zheng, L., Papagerakis, S., Schnell, S.D., Hoogerwerf, W.A., Papagerakis, P., 2011. Expressions of clock genes in developing tooth. Gene. Expr. Patterns. 11, 202-206.

Zheng, L., Seon, Y.J., Mourao, M.A., Schnell, S., Kim, D., Harada, H., Papagerakis, S., Papagerakis, P. 2013. Circadian rhythms regulate amelogenesis. Bone. 55, 158-165. 